\title{
Stomatognathic System
}

National Cancer Institute

\section{Source}

National Cancer Institute. Stomatognathic System. NCI Thesaurus. Code C13069.

The mouth, jaws, and other related structures that are involved in speech, mastication, and deglutition. 